\title{
IS1500, an IS3-like element from Leptospira interrogans
}

\author{
Caroline Boursaux-Eude, ${ }^{1}$ Isabelle Saint Girons ${ }^{1}$ and Richard Zuerner ${ }^{2}$
}

Author for correspondence: Richard Zuerner. Tel: +1 5152398392 . Fax : +1 5152398458.
e-mail: rzuerner @ asrr.arsusda.gov

1 Unité de Bactériologie Moléculaire et Médicale, Institut Pasteur, 75724, Paris Cedex 15, France

2 Leptospirosis and Mycobacteriosis Research Unit, National Animal Disease Center, Agricultural Research Service, US Department of Agriculture, PO Box 70, Ames, IA 50010, USA

\begin{abstract}
Copies of an insertion-sequence (IS)-like element were isolated from two closely related serovars of Leptospira interrogans sensu stricto. Nucleotide sequence analysis of the $\mathbf{1 2 3 6}$ bp element showed a characteristic IS structure with terminal imperfect inverted repeats (IRs) flanking a 1159 bp central region. This element was designated IS1500. Four open reading frames (orfA-orfD) were found in the central ' unique' region of IS1500. Similarities were detected between ORFA and ORFB and the putative transposases from members of the IS3 family of transposable elements. IS1500 or IS1500-like sequences were also detected in all other pathogenic leptospiral serovars, but not in the saprophytic species $L$. biflexa. Differences in IS1500 copy numbers in members of the same species suggest that this element can transpose. Physical mapping of IS1500 insertions in L. interrogans serovars icterohaemorrhagiae and pomona showed insertions were only on the large chromosomal replicon. The location of some IS1500 insertions coincides with regions of the genome that have undergone large rearrangements.
\end{abstract}

Keywords: insertion sequence, Leptospira, IS3-like

\section{INTRODUCTION}

Transposable elements are specific DNA sequences that can insert into non-homologous sites in various genomes. Insertion sequence (IS) elements are a class of transposable elements found in bacteria (Galas \& Chandler, 1989). Typically, IS elements range in size from about 700 to $2500 \mathrm{bp}$ and contain one or more open reading frames (ORFs). These ORFs usually encode proteins associated with transposition of the element. Inverse repeats (IRs) about 10-40 bp long are usually (but not always) found at the ends of IS elements (Galas \& Chandler, 1989). Insertion of an IS at a new site often generates a small duplication of part of the target DNA. Most well-studied IS elements are found in the Enterobacteriaceae, and much of our knowledge of the mechanisms of transposition comes from these studies (Galas \& Chandler, 1989). In recent years IS or IS-like elements have been isolated from nearly all evolutionary branches of bacteria, including spirochaetes (Pacciarini et al., 1992; Saint Girons et al.,

Abbreviations: CFGE, continuous-field gel electrophoresis; IR, inverted repeat; IS, insertion sequence; PFGE, pulsed-field gel electrophoresis.

The GenBank accession numbers for the nucleotide and derived protein sequences reported in this paper are U13012 (IS1500A) and U13013 (IS1500B).
1992; Woodward \& Sullivan, 1991; Zuerner et al., 1993a, b; Zuerner, 1994).

We are studying pathogenic spirochaetal bacteria in the genus Leptospira. Until recently all pathogenic members of the genus Leptospira were classified as Leptospira interrogans sensu lato. DNA homology studies showed the existence of extensive heterogeneity within L. interrogans sensu lato (Yasuda et al., 1987; Ramadass et al., 1992). These studies led to the reclassification of $L$. interrogans sensu lato into seven distinct species: $L$. borgpetersenii; $L$. inadai; L. interrogans sensu stricto; L. kirschneri; L. noguchii; L. santarosai; and L. weilii (Yasuda et al., 1987; Ramadass et al., 1992). There are no known mechanisms of genetic exchange between members of the genus Leptospira. Therefore, little is known about the genetics of these bacteria.

We recently showed evidence for gross alterations (inversions, deletions and insertions) in the genetic organization of two closely related serovars of $L$. interrogans sensu stricto (Zuerner et al., 1993b). We hypothesized that recombination between like copies of repetitive DNA may be used to generate the rearrangements detected during physical mapping studies. Several different types of repetitive DNA, including ISlike elements, occur in the leptospiral genome (Pacciarini 
et al., 1992; Ralph \& McClelland, 1993; Saint Girons et al., 1992; Van Eys et al., 1988; Woodward \& Sullivan, 1991 ; Zuerner, 1993, 1994; Zuerner et al., 1993a, b).

Studies of $L$. borgpetersenii provide insight into how ISlike elements contribute to the fluidity of the leptospiral genome. An IS-like element, IS1533, has been isolated from $L$. borgpetersenii and characterized (Woodward \& Sullivan, 1991; Zuerner \& Bolin, 1988; Zuerner, 1994). This element belongs to the recently recognized IS110 family of transposable elements (Zuerner, 1994). The genomes of different leptospiral serovars contain between zero and sixty copies of IS1533-related sequences (Zuerner $\&$ Bolin, 1990). Since the copy numbers differ in different serovars and among isolates of the same serovar, IS1533 is likely to be an active transposable element (Zuerner \& Bolin, 1990; Zuerner et al., 1993a; Zuerner, 1994). Analysis of the $L$. borgpetersenii serovar bardjo genome suggests that IS1533 may be involved in chromosomal rearrangements (Zuerner et al., 1993a). Pulsed-field gel electrophoresis (PFGE) studies of $L$. interrogans sensu lato reveals extensive heterogeneity (Herrmann et al., 1991, 1992) suggesting that this is a common phenomenon throughout this genus.

During construction of physical and genetic maps of $L$. interrogans serovars icterobaemorrbagiae strain Verdun (Baril et al., 1992) and pomona strain RZ11 (Zuerner, 1991) several additional repetitive sequence elements were isolated, including an element related to the IS 3 family of insertion elements. In this study we characterize copies of an IS3-like element from $L$. interrogans, and report its distribution in the genus Leptospira.

\section{METHODS}

Bacterial strains and plasmids. Leptospira strains (Table 1) were cultivated in EMJH medium (Ellinghausen \& McCullough, 1965; Johnson \& Harris, 1967) with agitation at $30^{\circ} \mathrm{C}$ or $33^{\circ} \mathrm{C}$. Virulent L. interrogans strain Verdun was verified for virulence in guinea pigs, and its avirulent derivative was obtained by continuous in vitro subcultures. Escherichia coli strains XL1-Blue (Stratagene) and $\mathrm{INV} \mathrm{F}^{\prime}$ (Invitrogen) were cultivated in either Luria-Bertani (LB) or DYT media (Miller, 1972) at $37^{\circ} \mathrm{C}$. Plasmids pUC18, pCRII (Invitrogen) and pBluescript $\mathrm{KSII}+/-$ (Stratagene) were used as cloning vectors. E. coli containing tecombinant plasmids was cultivated in the presence of either $100 \mu \mathrm{g}$ ampicillin $\mathrm{ml}^{-1}$ or $50 \mu \mathrm{g}$ kanamycin $\mathrm{ml}^{-1}$.

DNA electrophoresis and hybridization. Genomic DNA was prepared and separated by either continuous-field gel electrophoresis (CFGE) or PFGE using the protocols described previously by Baril et al. (1992), Zuerner (1991) and Zuerner $e t$ al. (1993b). Electrophoretically separated DNA was transferred to nylon membranes and used for hybridization analysis as described previously by Baril et al. (1992) and Zuerner (1991). Hybridization probes were prepared from cloned and uncloned PCR products or cloned genomic sequences. Probes were made with either digoxigenin-dUTP by random hexanucleotide priming reactions using a kit from Boehringer Mannheim, or $[\alpha-$ $\left.{ }^{32} \mathrm{P}\right] \mathrm{dATP} \quad\left(600 \mathrm{Ci} \mathrm{mmol}^{-1}, \quad 22 \cdot 2 \mathrm{TBq} \mathrm{mmol}^{-1}\right.$; ICN Pharmaceuticals) by nick translation using a kit from GibcoLife Technologies. Visualization of hybridization results was done as described previously by Baril et al. (1992) and Zuerner (1991).

PCR. Three different sets of primers were used in PCR reactions to amplify $L$. interrogans DNA. The amplified DNAs were either used directly for probe synthesis or were first cloned into plasmid vectors. Primer set 1 (5'-ATT-CTA-AGT-TAG-TGTGCA-3' and 5'-AGA-ATT-TCT-ATC-ACC-GAA-3') amplified between nucleotide 860 of IS1500 and a sequence downsteam of IS1500. Primer set 2 (5'-AAA-GAA-GGA-CTC-AGCGAC-TGC-G-3' and 5'-TTC-GAT-TCA-AAG-CAT-GGCTAA-CG-3') amplified between 396 and 1056 of IS1500B (note that the primer starting at nucleotide 1056 encompasses a segment of sequence divergence between IS1500 $A$ and IS1500B). Primer set 3 (5'-ATG-GAA-ACT-CAT-CGA-TTTGA-3' and 5'-TCG-ATC-CGA-ATG-AAA-AAC-TA-3') amplified between nucleotides 373 and 942 of IS1500. Amplifications using primer sets 1 and 3 were done in reaction mixtures containing $10 \mathrm{mM}$ Tris $/ \mathrm{HCl}, \mathrm{pH} 8.4,0.01 \%$ gelatin, $50 \mathrm{mM} \mathrm{KCl}, 1.5 \mathrm{mM} \mathrm{MgCl}, 200 \mu \mathrm{M}$ dNTPs, approximately $5 \mathrm{ng}$ of each primer $\mu^{-1}$, and approximately $6 \mathrm{ng}$ template $\mu \mathrm{l}^{-1}$. Amplification reactions for primer set 2 were done in reaction

Table 1. Leptospira strains used in this study

\begin{tabular}{|lll|}
\hline Species & \multicolumn{1}{c|}{ Serovar } & Strain \\
\hline L. interrogans & icterabaemorrbagiae & Verdun virulent \\
& $\begin{array}{l}\text { icterobaemorrhagiae } \\
\text { pomona }\end{array}$ & Verdun avirulent \\
& copenhageni & RZ11 \\
& lai & M20 \\
& lora & Lai \\
& australis & Lora \\
& ballum & Ballico \\
& louisiana & Mus 127 \\
L. borgpetersenii & celledoni & LSU 1945 \\
L. nogucbii & shermani & Celledoni \\
L. weilii & grippotyphosa & $1342 \mathrm{~K}$ \\
L. santarosai & ranarum & Moskva V \\
L. kirschneri & patoc & Ranarum \\
L. inadai & Patoc \\
L. biflexa & & \\
\hline
\end{tabular}


(a)

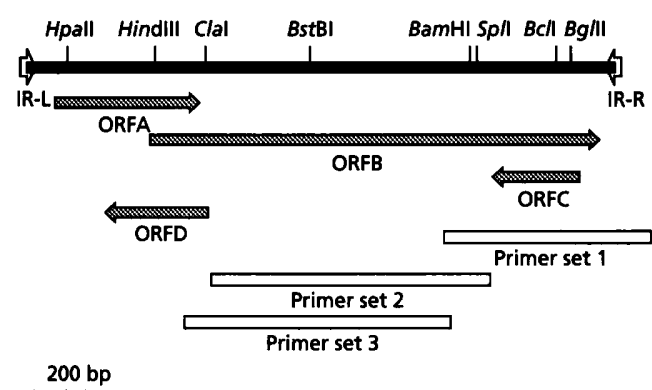

(b)

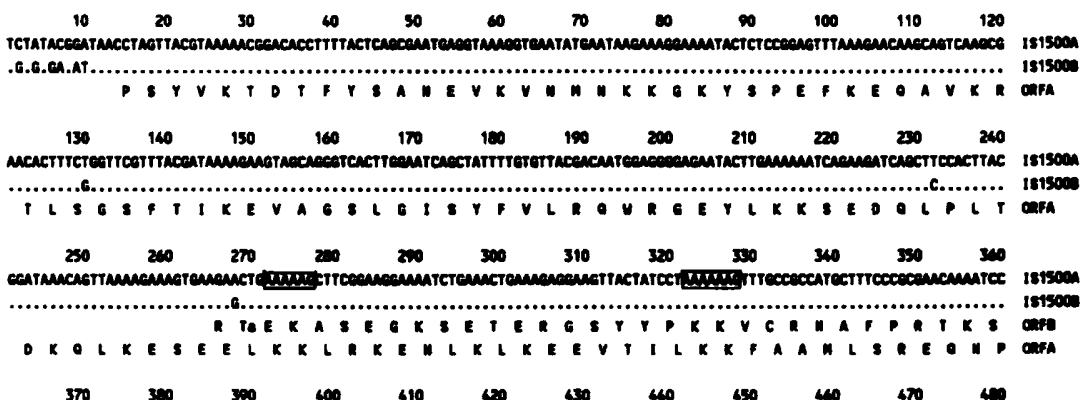

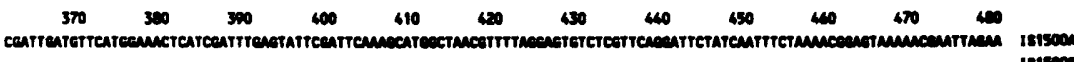
(181500 L

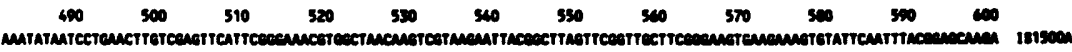

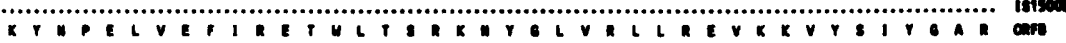

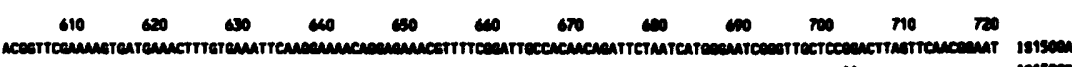

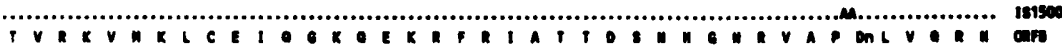

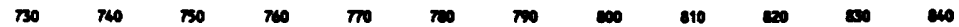

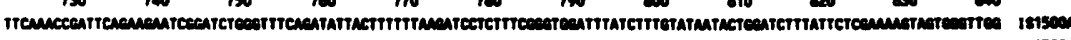

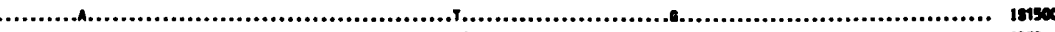

Fo the $x=1$ o

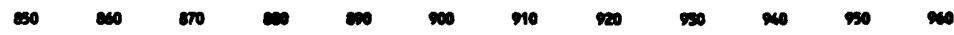

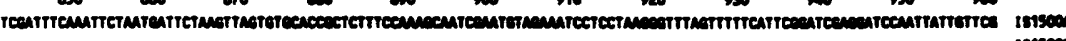
, n

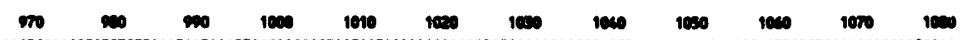

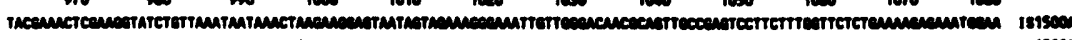

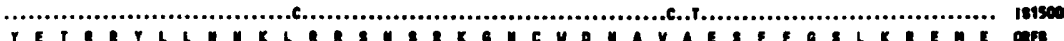

$\begin{array}{llllllllllll}1000 & 1100 & 1110 & 1120 & 1130 & 1140 & 1150 & 1160 & 1170 & 1180 & 1190 & 1200\end{array}$

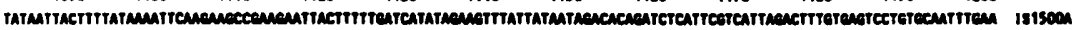
....................................................................................................... 181800

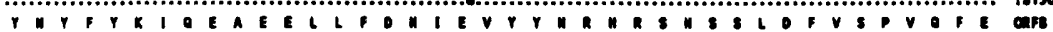
$1210 \quad 1220 \quad 1230 \quad 1260 \quad 1200$

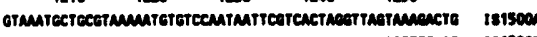
.............................................entroc.nc isisod

Fig. 1. IS1500 nucleotide sequence analysis. (a) Structural features of IS1500. Selected restriction sites in IS1500, location and direction of ORFs, and IRs (arrowheads) are shown. The locations of the PCR-amplified DNA using three different primer sets are shown with boxes. (b) Nucleotide sequence of IS1500. The nucleotide sequences of IS1500A and IS1500B are shown, with homologous nucleotides in IS1500B shown as dots. The predicted amino acid sequences for ORFA and B are shown. Amino acid changes in the IS1500B ORFB sequence are shown in lower case next to the corresponding amino acid from the IS1500A ORFB sequence (which is shown in upper case). The putative translational shift sequences are blocked.

mixtures containing $10 \mathrm{mM}$ Tris/ $\mathrm{HCl}, \mathrm{pH} 9 \cdot 0,0 \cdot 1 \%$ Triton $\mathrm{X}$ $100,50 \mathrm{mM} \mathrm{KCl}, 4 \mathrm{mM} \mathrm{MgCl}$, $200 \mu \mathrm{M}$ dNTPs, approximately $2.5 \mathrm{ng}$ of each primer $\mu^{-1}$, and approximately $6 \mathrm{ng}$ template $\mu \mathrm{l}^{-1}$. Reactions $(50 \mu \mathrm{l}$ or $100 \mu \mathrm{l}$ vol.) were carried out either as described previously by Zuerner et al. (1993b) (primer set 2 ) or for 28 cycles of: $95^{\circ} \mathrm{C}$ for $1 \mathrm{~min} ; 44^{\circ} \mathrm{C}$ for $1 \mathrm{~min}$; and $72^{\circ} \mathrm{C}$ for $3 \mathrm{~min}$ (primer set 1). Primer set 3 was used to amplify DNA using the same protocol as primer set 1 but with an annealing temperature of $50^{\circ} \mathrm{C}$, and $1.5 \mathrm{~min}$ extension at $72^{\circ} \mathrm{C}$. Probes synthesized from DNA amplified by primer sets 1 and 2 were used to screen genomic libraries for copies of IS1500. A probe synthesized from DNA amplified by primer set 3 was used to determine distribution, copy number and physical location of IS1500 insertions in the genome. The PCR products were cloned by ligation with SmaI-cleaved pUC18 DNA using the SureClone ligation kit (Pharmacia), or into pCRII using a kit from Invitrogen. Ligations were transformed into E. coli strains $\mathrm{XL1}$-Blue or INV $\alpha \mathrm{F}^{\prime}$ using standard techniques.

DNA sequencing and computer analysis. Nucleotide sequencing was done by dideoxynucleotide chain-termination reactions (Sanger et al., 1977) on double-stranded templates with T7 DNA polymerase (Pharmacia or US Biochemical) in the presence of ${ }^{35}$ S $] \mathrm{dATP} \alpha \mathrm{S}$ (Amersham). Reaction products were separated by electrophoresis through polyacrylamide-urea gels. Gels were either dried directly or first fixed with $10 \%(\mathrm{v} / \mathrm{v})$ methanol $/ 10 \%(\mathrm{v} / \mathrm{v})$ acetic acid. Dried gels were used to expose XAR film (Kodak) at $-80^{\circ} \mathrm{C}$. Nucleic acid and deduced amino acid sequences were analysed by BLAST (Altschul et al., 1990), GCG (Genetics Computer Group), PC-Gene, Bionet (Intelligenetics), CLUSTAL (Higgins \& Sharp, 1988) and PHYLIP version 3.5c (J. Felsenstein, Department of Genetics, University of Washington, Seattle) software, and by visual inspection. 
(a)

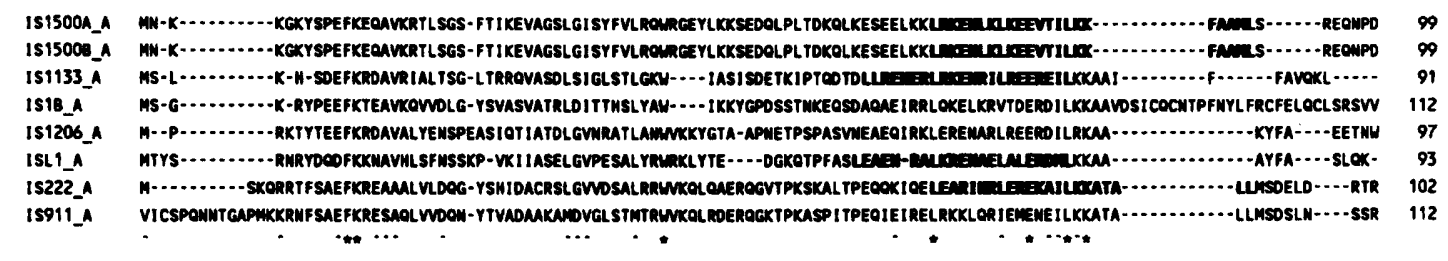

(b)

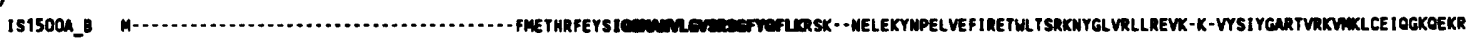

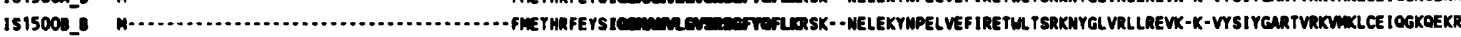
153 . IS600_.

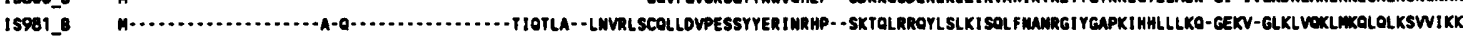
IST1_B

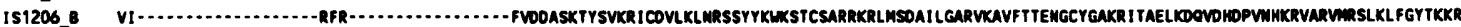

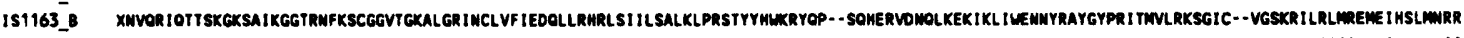
136

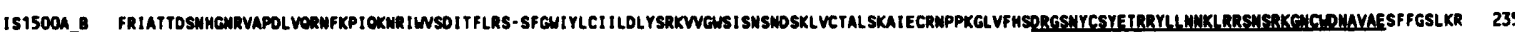

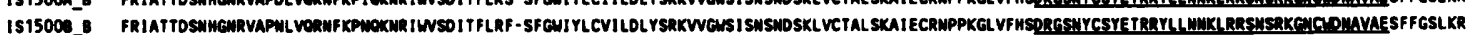

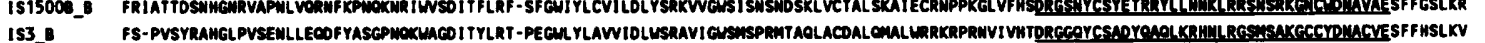

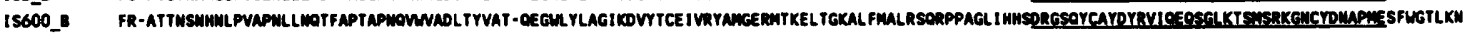

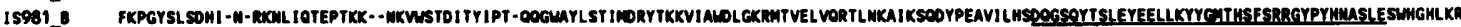

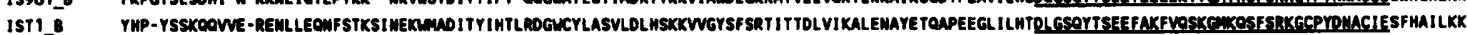

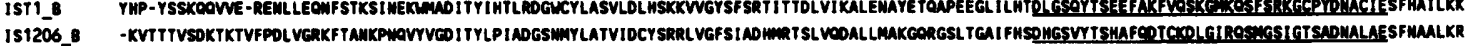

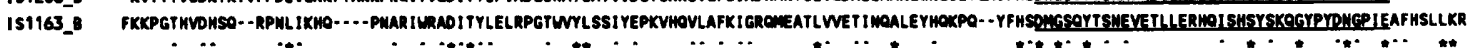

IS1500M_B E-MEYWY-FYXIOEAEELLFOMIEWYYMRMSHSSLDFVSPVOFEWH-.....-M 282 IST5008_B E-AEYWY-FYKIOEAEELLFOHIEWYYWRMRSUSSLDFVSPVOFEWW-......MA 282

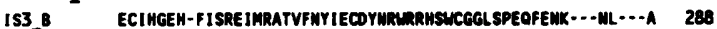

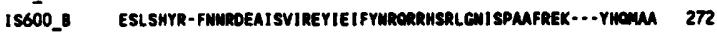
15981_B EWYOFK-YKMFEEAYOSIFWIEAFYMSKRIMOSLGYLTPIOFE-K...V-..-SA 279

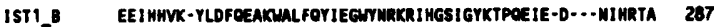
IS1206_8 EVLCOSKTFMUOLPCRRDVFRUCTR-YIMVRRHSUCKYLAPAVFEKRCPAILKSAS 298 IS1163_B E-FAFOTTFSNFEDLVIRTSWYIS-UFWSORIRTSV -.................. 302

Fig. 2. Comparison of IS1500-encoded proteins. (a) ORFAs from several IS3-like elements are compared. IS1500A-A and IS1500B-A refer to the ORFA proteins from IS1500A and IS1500B, respectively. (b) ORFBs from several IS3-like elements are compared. IS1500A-B and IS1500B-B refer to the ORFB proteins from IS1500A and IS1500B, respectively. Dashes (-) were inserted to optimize the alignments. Amino acids identical $(*)$ or similar $(\wedge)$ to those in the IS1500-encoded proteins are shown below the sequences. The conserved $D_{35} E$ motifs regions are underlined. Leucine zipper motifs (ORFA) and helix-turn-helix motifs (ORFB) in the IS1500-encoded proteins are in boldface type. Protein sequences were from: IS1B (Volkert et al., 1994; accession number L20943), IS3 (Timmerman \& Tu, 1985; accession number X02311), IS222 (Kropinski et al., 1994; accession number U00100), IS600 (Matsutani et al., 1987; accession number X05952), IS911 (Prere et al., 1990 ; accession number X17613), IS981 (Polzin \& McKay, 1991; accession number M33933), IS1133 (Chiou \& Jones, 1993; accession number Z12167), IS1163 (Skaugen \& Nes, 1994; accession number X75164), IS1206 (Bonamy et al., 1994; accession number X69104), ISL1 (ShimizU-Kadota et al., 1985, accession number X02734), and IST1 (accession number D10543).

\section{RESULTS}

\section{Nucleotide sequence analysis}

During earlier physical genomic mapping studies of $L$. interrogans (serovar icterobaemorrbagiae strain Verdun and serovar pomona strain RZ11) several cloned sequences were independently isolated and found to hybridize with multiple restriction fragments (Baril et al., 1992; Zuerner, 1993; Zuerner et al., 1993b). Cross-hybridization analysis showed that several different clones shared common sequences, suggesting that they were part of a related group of repetitive elements. Nucleotide sequence analysis showed the clones from strain Verdun contained sequences homologous to the $5^{\prime}$ end of IS 3 from E. coli, while the clones from strain RZ11 were homologous to the $3^{\prime}$ end of IS3. Both sets of clones started at a conserved Bam $\mathrm{HI}$ site and extended in opposite directions from each other. A composite sequence was generated by combining the sequences from strains Verdun and RZ11 at the BamHI site, then designing PCR primers which could extend across this site. These primers directed amplification reactions, the products of which were used to screen genomic libraries from each strain for clones containing copies of the element. The nucleotide sequences from the genomic clones were determined.

One complete copy of the IS3-like repetitive element was characterized from each $L$. interrogans strain (Verdun and RZ11). The repetitive elements were $1236 \mathrm{bp}$ in size and $98 \%$ identical in sequence. Both copies of the element have a DNA content of $35 \% \mathrm{G}+\mathrm{C}$ which is approximately the same as genomic DNA of L. interrogans. The termini of the elements from each strain contained imperfect inverted repeats (IRs) flanking $1159 \mathrm{bp}$ 


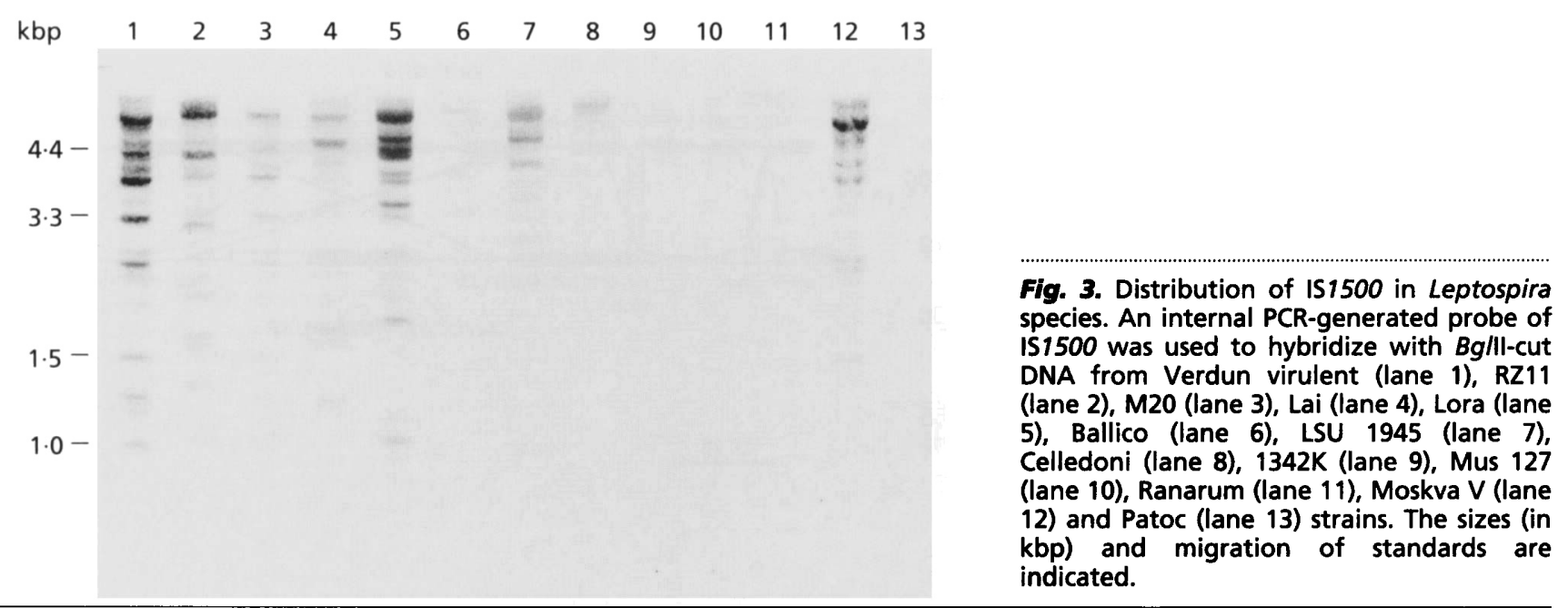

'unique' regions (Fig. 1). These 'unique' regions contained four potential ORFs ( $\operatorname{rrf} A-\operatorname{orf} D)$. Because the cloned elements have characteristic IS features they were designated IS1500, and called IS1500 A (from strain Verdun) and IS1500B (from strain RZ11). The IRs are unequal in size with the left IR being $38 \mathrm{bp}$ in length with the sequence 5'-TAA-CCT-AGT-TAC-GTA-AAAACG-GAC-ACC-TTT-TAC-TCA-GC-3', and the right IR being 39 bp in length with the sequence $5^{\prime}$-TAA-CCTAGT-GAC-GAA-TTA-TTG-GAC-ACA-TTT-TTACGC-AGC-3'. Although the two copies of IS1500 shown share a cytosine immediately next to the right IR other copies of IS1500 do not (data not shown). Other sequences immediately next to the copies of IS $1500 A$ and $B$ shown are different (Fig. 1) showing that the two copies are from different insertions in the leptospiral genome.

The IS1500 sequences were compared to the combined EMBL, PDB, GenBank, PIR, and SwissProt databases using BLAST and FASTA (GCG) algorithms. The $5^{\prime}$ portion of IS 1500 is approximately $70 \%$ similar to a $620 \mathrm{bp}$ repetitive element characterized from $L$. interrogans serovar bardjo type bardjoprajitno described previously (Savio et al., 1994; accession number X58829). IS1500 also shares sequence similarity to the IS3 family of transposable elements (see below).

\section{Protein coding potential}

The 'unique' region of IS1500 contains four ORFs. Starting from the left IR the first ORF $(\operatorname{orf} A)$ spans nucleotides 14-364 (using the coordinates in Fig. 1) and has the potential to encode a $11765 \mathrm{Da}$ protein (starting with GTG at nucleotide 62). The second ORF (orfB) overlaps ORFA, spanning nucleotides 265 and 1212, is the largest, and has the potential to encode a $33355 \mathrm{Da}$ protein (starting with ATG at nucleotide 367 ). There are two small ORFs on the complementary strand of IS1500: orfC (between nucleotides 1234 and 913) has the potential to encode a $10678 \mathrm{Da}$ protein (starting with ATG at nucleotide 1171); and orfD (between nucleotides 420 and
227) has the potential to encode a $5908 \mathrm{Da}$ protein (starting with ATG at nucleotide 384).

Searches of the protein and nucleotide databases using the BLAST and FASTA algorithms showed that the predicted ORFA and ORFB proteins were similar to the predicted proteins encoded by the IS 3 family of transposable elements. Using the BLAST scores as a guide, the protein sequences most similar to the predicted IS1500-encoded ORFA and ORFB proteins were aligned using CLUSTAL and analysed with PHYLIP software. Those sequences found to be most alike to the IS1500 proteins are shown in Fig. 2. Searches of the databases failed to detect sequences with significant similarity to the ORFC or ORFD proteins.

Analysis of the predicted IS1500-encoded proteins using PROSITE suggested that ORFA has a leucine zipper motif (Fig. 2) common among many DNA-binding proteins (Landschulz et al., 1988). Some ORFA proteins of other IS3-like elements also contain the leucine zipper motifs. ORFB has a helix-turn-helix motif (Fig. 2) which is also common to many DNA-binding proteins (Brennan \& Matthews, 1989).

\section{IS1500 copy number in Leptospira species}

The minimum number of IS1500-like sequences in different members of the genus Leptospira was determined by Southern blot hybridization of CFGE-separated BglIIdigested genomic DNA hybridized with an internal IS1500 probe (see Methods). Since the PCR-generated IS1500 probe did not span the BglII site in IS $1500 \mathrm{~A}$ or IS $1500 B$, a single hybridizing fragment was assumed to represent a single copy of IS 1500 or IS1500-like sequence. Fragments of varying intensity were detected (Fig. 3), and only the more intense bands were considered for determining approximate copy number. This approach may yield a conservative estimate of IS 1500 copy number since more than one copy may reside on the same fragment or there may be two or more comigrating fragments which hybridize with the probe. There were at least eight copies 
(a)

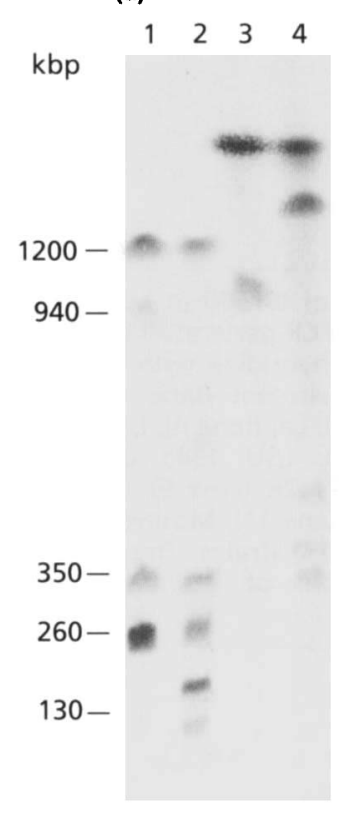

(b)

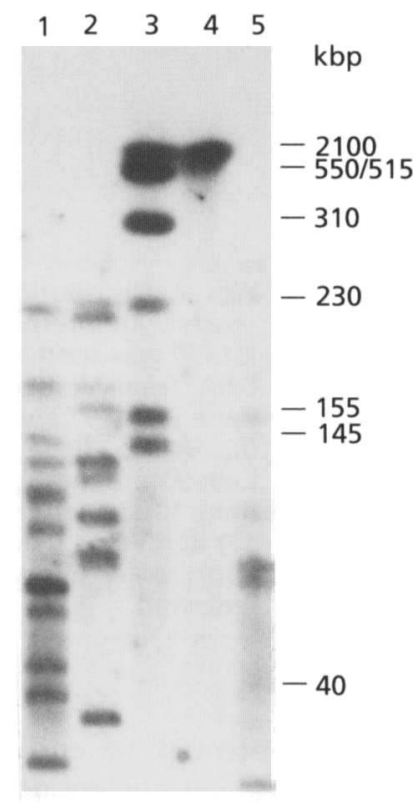

(c)

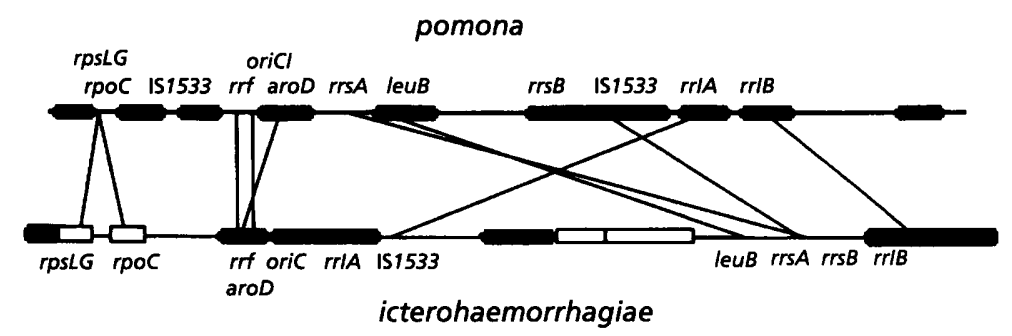

$500 \mathrm{~kb}$

\begin{abstract}
Fig. 4. Localization of IS1500 on the physical map of the $L$. interrogans genome. (a) Hybridization of an internal IS1500 probe with Verdun DNA digested with Notl (lane 1), Notl and Ascl (lane 2), Ascl (lane 3) and Srfl (lane 4). Sizes of the Notl fragments which hybridized with the probe are shown adjacent to lane 1. (b) Hybridization of clone KB4 with restrictionendonuclease-digested, PFGE-separated, RZ11 DNA. DNA was digested with Apal (lane 1), BssHII (lane 2), NotI (lane 3), Sfil (lane 4) and Smal (lane 5). Sizes of the Notl and a $40 \mathrm{kbp}$ Apal fragment which hybridized with the probe are shown adjacent to lane 5 . (c) Comparison of IS1500 distribution in L. interrogans serovar icterohaemorrhagiae strain Verdun and serovar pomona strain RZ11. Approximate locations for 151500 insertions in the genomes of strains RZ11 (top) and Verdun (bottom) are shown as blocks on the genetic map. Boxes indicating IS1500 insertions are shown as different sizes because they span the entire length of restriction fragments used for locating the insertion. For strain Verdun the presence of co-migrating fragments complicates the interpretation of the hybridization data, and probable (not confirmed) locations are shown as open boxes. Note that for strain Verdun part of the Notl B fragment is located at the left-hand side of the linearized physical map while the rest of this fragment is located at the right end, and likely constitutes a single insertion. Selected markers are shown. Approximate regions of the genome which are rearranged (inverted or having an insertion) between these two strains are shown by the lines between the two maps. The endpoints of the rearrangements are not known.
\end{abstract}

of IS1500 in L. interrogans strain Verdun (Fig. 3) and there were no differences between virulent strain Verdun and its avirulent derivative (data not shown). Strain RZ11 had about 11 copies of IS1500 (Fig. 3, and data not shown). There were at least 14 copies of IS 1500 in both L. nogucbii strain LSU 1945 and L. kirschneri strain Moskva V, six copies in $L$. weilii strain Celledoni, two copies in $L$. santarosai strain $1342 \mathrm{~K}$, and one copy each in $L$. borgpetersenii strain Mus 127 and $L$. inadai strain Ranarum (Fig. 3). No sequences hybridizing with the IS 1500 probe were detected in L. biflexa (Fig. 3). Because some of the copies detected in $B g / \mathrm{II}$ digests of leptospiral DNA were below the unit size of IS1500 it is likely that sequence heterogeneity resulting in 'new' $B g / \mathrm{II}$ sites within the region spanned by the probe is present among different IS 1500 or IS 1500 -like elements.

\section{Localization of IS1500 on the physical maps of $L$. interrogans}

Comparison of the physical and genetic maps of $L$. interrogans strains Verdun and RZ11 showed the presence of several large rearrangements which could be the result of recombination between repetitive DNA (Zuerner $e$ t al., 1993b). As a first step in assessing the possible role of IS1500 in generating some of these rearrangements we mapped the approximate location of IS1500 insertions on the physical maps of these two strains. The internal IS1500 probe was used to localize insertion sites in strain Verdun. This probe hybridized with NotI fragments A, B, C, F and H of strain Verdun (Fig. 4a). Because the Not I C, $\mathrm{F}$ and $\mathrm{H}$ bands each contain two fragments $(\mathrm{C} 1, \mathrm{C} 2, \mathrm{~F} 1$, F2, H1 and H2) additional hybridization experiments were done with DNA digested with both NotI and $A s c \mathrm{I}$. Results of these experiments confirmed that copies of IS 1500 are on the C1 and F2 fragments, and suggest that insertions may also be on the C2 and F1 fragments (Fig. $4 \mathrm{a}$, and data not shown). Lack of suitable restriction sites in or near the NotI $\mathrm{H} 1$ and $\mathrm{H} 2$ fragments prevented us from determining if IS1500 is located on one or both fragments. Probes synthesized from cloned copies of IS1500B hybridized with NotI fragments A, B, C, E, F, H, and I of strain RZ11 (Fig. 4b, and data not shown). Further localization was made possible by following the hybridization patterns of the probe with $A p a \mathrm{I}, B s s \mathrm{HII}$ and SmaI (Fig. 4b) and AscI, SgrAI, Sse8387I and SrfI 
fragments (data not shown). The approximate positions of IS1500 insertions in the genomes of strains Verdun and RZ11 are shown on the physical maps (Fig. 4c). It is important to note that these maps are the most conservative interpretation of the hybridization data allowing for only one copy per set of hybridizing restriction fragments. Thus, if two elements are closely placed on the same fragment they were counted as a single insertion.

\section{DISCUSSION}

Genetic organization in L. interrogans sensu lato is fluid. Closely related strains can be differentiated by large chromosomal rearrangements (Herrmann et al., 1991, 1992; Zuerner et al., 1993b). We have hypothesized that the prevalence of repetitive DNA, including IS-like elements, in the leptospiral genome contributes to the generation of these rearrangements (Zuerner et al., 1993b). To understand better the potential involvement of repetitive DNA in generating these rearrangements we have initiated studies aimed at characterizing these elements. In this study we isolated and characterized different copies of an IS3-like element that we designated IS1500 from two closely related serovars of L. interrogans sensu stricto. This element has features characteristic of bacterial IS elements, including the presence of terminal IRs, and a central region containing ORFs. The lack of identical sequences immediately adjacent to the IRs suggests that IS1500 integrates without duplication of the target sequences as is often seen in other IS elements (Galas \& Chandler, 1989). Lack of conservation among sequences flanking IS1500 suggests that this element lacks a highly conserved target site for integration. It is important to note that the $5^{\prime}$ portion of IS1500 shares significant similarity to a 620 bp repetitive element cloned from L. interrogans serovar bardjo (Savio et al., 1994; accession number X58829) suggesting that related IS3like elements exist in the $L$. interrogans genome. Indeed, the presence of copies of this related element may account for variations in the hybridization signal seen in hybridization experiments with the IS1500-based probes (Fig. 3). The predicted IS1500-encoded proteins also share similarities to other IS3-like elements and to the $\mathrm{D}_{35} \mathrm{E}$ superfamily of transposases (Doak et al., 1994).

One hallmark of IS3-like transposable elements is the presence of overlapping ORFs encoding the putative transposases (Chandler \& Fayet, 1993; Galas \& Chandler, 1989; Polard et al., 1991; Schwartz et al., 1988). These ORFs typically start near the beginning of the central 'unique' region of the IS $(\operatorname{orf} A)$ and extend to very near the end of this region (orfB). In $E$. coli, IS 3, IS150 and IS911 each encode three proteins of about 10000,32000 and $42000 \mathrm{Da}$ in size (Sekine et al., 1994; Vögele et al., 1991; Polard et al., 1991). The two smaller proteins are products of $\operatorname{orf} A$ and $\operatorname{orf} B$, respectively, with translation of $\operatorname{orf} B$ being coupled with translation of $\operatorname{orf} A$ (Sekine et al., 1994). A (-1) translational shift fuses $\operatorname{orf} A$ with $\operatorname{orf} B$ when the ribosome encounters the sequence $A_{6} G$ (IS150 and IS911) or $\mathrm{A}_{4} \mathrm{G}$ (IS3) and yields the $42000 \mathrm{Da}$ protein. It is the ORFAB fusion protein which is thought to be the functional transposase. Like IS 3 and other members of the
IS 3 family, IS 1500 has an $\operatorname{orf} A$ and an $\operatorname{orf} B$, encoding proteins of about 11000 and $33000 \mathrm{Da}$. Two potential translational shift sequences $\left(A_{5} G\right.$ and $\left.A_{6} G\right)$ occur in the $\operatorname{orf} A-\operatorname{orf} B$ overlap (at nucleotides 265 and 364, respectively) and likely direct synthesis of an ORFAB fusion protein of about $45000 \mathrm{Da}$. Attempts to demonstrate synthesis of these proteins in vitro using cell-free extracts of $E$. coli have met with limited success; only the ORFA protein has been detected (data not shown).

The roles of the ORFA or ORFB proteins in the IS 3 family of elements are not well understood. It has been suggested that the IS 3 ORFA may repress transposition either by binding in a possible promoter for the IS3encoded genes (and thus block transcription) or, alternatively, this protein may bind to the IRs (and thus block transposase from binding its target) (Sekine et al., 1994). In contrast, the ORFA protein of IS911 appears to promote intermolecular transposition, but the mechanism by which this is achieved is unclear (Polard et al., 1991, 1992). While these differences have yet to be resolved it is interesting to note that the ORFA proteins of different IS3-like elements are not as well conserved as the ORFB proteins (Schwartz et al., 1988; Fig. 2). The IS1500 ORFA has a potential leucine zipper motif common among DNA-binding proteins (Landschulz et al., 1988). Leucine zipper motifs are also seen among ORFA proteins from some, but not all, members of the IS 3 family. Presence of a leucine zipper motif suggests that ORFA may interact with DNA as a dimer (Landschulz et al., 1988). In IS1500 the leucine zipper motif is lost in the ORFAB fusion protein, suggesting that ORFA and the ORFA portion of the ORFAB fusion protein are functionally different. The IS 1500 ORFB protein shares the $\mathrm{D}_{35} \mathrm{E}$ motif which is also seen in eukaryotic retrotransposons (Doak et al., 1994; Fayet et al., 1990). It has been suggested that the $\mathrm{D}_{35} \mathrm{E}$ motif has a functional role in catalysing part of the transposition reaction (Doak et al., 1994). The ORFB protein and the ORFB-portion of the ORFAB fusion protein contain a helix-turn-helix motif suggesting both proteins interact with DNA (Brennan \& Matthews, 1989). Further analysis is needed to define the functional regions of the IS-encoded proteins of the IS 3 family.

Unfortunately, there is no known method to study genetic exchange in $L$. interrogans. Thus there are no data regarding the ability of these elements to transpose. Differences in IS1500 copy numbers in different $L$. interrogans serovars, and the presence of IS1500 in each of the known species of pathogenic leptospiral serovars, suggests that this element may be transpositionally active. Further study is needed to show transposition of IS1500.

One aspect of particular interest to our laboratories is the generation of chromosomal rearrangements in $L$. interrogans. Evidence for the presence of two chromosomal replicons $(4 \cdot 4-4.7 \mathrm{Mb}$, and $350 \mathrm{~kb}$ in size) in L. interrogans sensu lato has been presented (Zuerner et al., 1993b). Comparison of genetic organization in two closely related serovars (icterobaemorrbagiae and pomona) shows that several chromosomal rearrangements have occurred in the large chromosomal replicons of these two serovars. Some of these rearrangements are inversions, spanning up to 
$34 \%$ of the large replicon. In several bacteria, including E. coli, regions of chromosomal instability can be mapped near IS elements (Birkenbihl \& Vielmetter, 1990; Umeda \& Ohtsubo, 1989). In L. interrogans serovars icterobaemorrbagiae and pomona strains Verdun and RZ11, all IS1500 insertions occur on the large chromosomal replicon (Fig. 4c), and many are located in regions of the chromosome containing rearrangements. Previously we found that IS1533-like sequences mapped near one of the rearranged segments of the chromosome (Zuerner et al., 1993b). While these data favour a possible role of the repetitive elements in contributing to the genomic heterogeneity seen within $L$. interrogans sensu lato, the techniques used to localize the elements only provide a low resolution map and alternative elements or genetic mechanisms could also contribute to generating chromosomal rearrangements. No differences in the IS1500 hybridization patterns were detected between virulent and avirulent Verdun strains, suggesting that IS1500 rearrangement does not play a role in the loss of virulence of these strains. However, potential rearrangements involving other repetitive DNA species were not investigated. We are using information from this study to better localize the rearrangements and to determine if, or how, the rearrangements affect phenotype in $L$. interrogans.

\section{ACKNOWLEDGEMENTS}

We thank Pascale Amouriaux-Bourhy and Danielle Margarita for preliminary experiments, Iain G. Old, Betsy Bricker and Shirley Halling for helpful discussions, and Annette Olson and John Foley for technical assistance.

\section{REFERENCES}

Altschul, S. F., Gish, W., Miller, W., Myers, E. W. \& Lipman, D. J. (1990). Basic local alignment search tool. $J$ Mol Biol 215, 403-410.

Baril, C., Herrmann, J. L., Richaud, C., Margarita, D. \& Saint Girons, I. (1992). Scattering of the rRNA genes on the physical map of the circular chromosome of Leptospira interrogans serovar icterohaemorrhagiae. J Bacteriol 23, 7566-7571.

Birkenbihl, R. P. \& Vielmetter, W. (1990). Complete maps of IS1, IS2, IS3, IS4, IS5, IS 30, and IS150 locations in Escherichia coli K12. Mol \& Gen Genet 220, 147-153.

Bonamy, C., Labarre, J., Reyes, O. \& Leblon, G. (1994). Identification of IS 1206, a Corynebacterium glutamicum IS3-related insertion sequence and phylogenetic analysis. Mol Microbiol 14, 571-581.

Brennan, R. G. \& Matthews, B. W. (1989). The helix-turn-helix DNA binding motif. J Biol Chem 264, 1903-1906.

Chandler, M. \& Fayet, O. (1993). Translational frameshifting in the control of transposition in bacteria. Mol Microbiol 7, 497-503.

Chiou, C.-S. \& Jones, A. L. (1993). Nucleotide sequence analysis of a transposon ( $\operatorname{Tn} 5393)$ carrying streptomycin resistance genes in Erwinia amylovora and other gram-negative bacteria. J Bacteriol 175, $732-740$.

Doak, T. G., Doerder, F. P., Jahn, C. L. \& Herrick, G. (1994). A proposed superfamily of transposase genes: tranposon-like elements in ciliated protozoa and a common ' $\mathrm{D}_{35} \mathrm{E}$ ' motif. Proc Natl Acad Sci US A 91, 942-946.

Ellinghausen, H. C. \& McCullough, W. G. (1965). Nutrition of Leptospira pomona and growth of 13 other serotypes: fractionation of oleic albumin complex and medium bovine albumin and polysorbate 80. Am J Vet Res 26, 45-51.

Fayet, O., Ramond, P., Polard, P., Prere, M. F. \& Chandler, M. (1990). Functional similarities between retroviruses and the IS3 family of bacterial insertion sequences. Mol Microbiol 4, 1771-1774.

Galas, D. J. \& Chandler, M. (1989). Bacterial insertion sequences. In Mobile DN A, pp. 109-162. Edited by D. E. Berg \& M. M. Howe. Washington, DC: American Society for Microbiology.

Herrmann, J. L., Baril, C., Bellenger, E., Perolat, P., Baranton, G. \& Saint Girons, I. (1991). Genome conservation in isolates of Leptospira interrogans. J Bacteriol 173, 7582-7588.

Herrmann, J. L., Bellenger, E., Perolat, P., Baranton, G. \& Saint Girons, I. (1992). Pulsed-field gel electrophoresis of NotI digests of leptospiral DNA: a new rapid method of serovar identification. $J$ Clin Microbiol 30, 1696-1702.

Higgins, D. G. \& Sharp, P. M (1988). Clustal: a package for performing multiple sequence alignment on a microcomputer. Gene 73, 237-244.

Johnson, R. C. \& Harris, V. G. (1967). Differentiation of pathogenic and saprophytic leptospires. I. Growth at low temperatures. $J$ Bacteriol 94, 27- 31.

Kropinski, A. M., Farinha, M. A. \& Jansons, I. (1994). Nucleotide sequence of the Pseudomonas aeruginosa insertion sequence IS222: another member of the IS3 family. Plasmid 31, 222-228.

Landschulz, W. H., Johnson, P. F. \& McKnight, S. L. (1988). The leucine zipper; a hypothetical structure common to a new class of DNA binding proteins. Science 240, 1759-1764.

Matsutani, S., Ohtsubo, H., Maeda, Y. \& Ohtsubo, E. (1987). Isolation and characterization of IS elements repeated in the bacterial chromosome. $J$ Mol Biol 196, 445-455.

Miller, J. H. (1972). Experiments in Molecular Genetics. Cold Spring Harbor, NY: Cold Spring Harbor Laboratory.

Pacciarini, M. L., Savio, J. L., Tagliabu, S. \& Rossi, C. (1992). Repetitive sequences cloned from Leptospira interrogans serovar hardjo genotype hardjoprajitno and their application to serovar identification. J Clin Microbiol 30, 1243-1249.

Polard, P., Prere, M. F., Chandler, M. \& Fayet, O. (1991). Programmed translational frameshifting and initiation at an AUU codon in gene expression of bacterial insertion sequence IS911. J Mol Biol 222, 465-477.

Polard, P., Prere, M. F., Fayet, O. \& Chandler, M. (1992). Transposase-induced excision and circularization of the bacterial insertion sequence IS911. EMBO J 11, 5079-5092.

Polzin, K. M. \& McKay, L. L. (1991). Identification, DNA sequence, and distribution of IS981, a new, high-copy-number insertion sequence in Lactococci. Appl Environ Microbiol 57, 734-743.

Prere, M. F., Chandler, M. \& Fayet, O. (1990). Transposition in Shigella dysenteriae: isolation and analysis of IS911, a new member of the IS3 group of insertion sequences. J Bacteriol 172, 4090-4099.

Ralph, D. \& McClelland, M. (1993). Intervening sequence with conserved open reading frame in eubacterial $23 \mathrm{~S}$ rRNA genes. Proc Natl Acad Sci US A 90, 6864-6868.

Ramadass, P., Jarvis, B. D. W., Corner, R. J., Penny, D. \& Marshall, R. B. (1992). Genetic characterization of pathogenic Leptospira species by DNA hybridization. Int J Syst Bacteriol 42, 215-219.

Saint Girons, I., Norris, S. J., Gobbel, U., Meyer, J., Walker, E. M. \& Zuerner, R. (1992). Genome structure of spirochetes. Res Microbiol 143, 615-621.

Savio, M. L., Rossi, C., Fusi, P., Tabliabue, S. \& Pacciarini, M. L. (1994). Detection and identification of Leptospira interrogans 
serovars by PCR coupled with restriction endonuclease analysis of amplified DNA. J Clin Microbiol 32, 935-941.

Sanger, F., Nicklen, S. \& Coulson, A. R. (1977). DNA sequencing with chain-terminating inhibitors. Proc Natl Acad Sci USA 74, 5463-5467.

Schwartz, E., Kröger, M. \& Rak, B. (1988). IS150: distribution, nucleotide sequence and phylogenetic relationships of a new $E$. coli insertion element. Nucleic Acids Res 16, 6789-6802.

Sekine, Y., Eisaki, N. \& Ohtsubo, E. (1994). Translational control in production of transposase and in transposition of insertion sequence IS3. $J$ Mol Biol 235, 1406-1420.

Shimizu-Kadota, M., Kiwaki, M., Hirokawa, H. \& Tsuchida, N. (1985). ISL1: a new transposable element in Lactobacillus casei. Mol \& Gen Genet 200, 193-198.

Skaugen, M. \& Nes, I. F. (1994). Transposition in Lactobacillus sake and its abolition of lactocin S production by insertion of IS1163, a new member of the IS3 family. Appl Environ Microbiol 60, 2818-2825.

Timmerman, K. P. \& Tu, C. P. D. (1985). Complete sequence of IS3. Nucleic Acids Res 13, 2127-2139.

Umeda, M. \& Ohtsubo, E. (1989). Mapping of insertion elements IS1, IS2, and IS 3 on the Escherichia coli K-12 chromosome. Role of the insertion elements in formation of Hfrs and $\mathrm{F}^{\prime}$ factors and in rearrangement of bacterial chromosomes. J Mol Biol 208, 601-614.

Van Eys, G. J. J. M., Zall, J., Schoone, G. J. \& Terpstra, W. J. (1988). DNA hybridization with hardjobovis specific recombinant probes as a method for type discrimination of Leptospira interrogans serovar bardjo. J Gen Microbiol 134, 567-574.

Vogele, K., Schwartz, E., Welz, C., Schiltz, E. \& Rak, B. (1991). High-level ribosomal frameshifting directs the synthesis of IS150 gene products. Nucleic Acids Res 19, 4377-4385.

Volkert, M. R., Loewen, P. C., Switala, J., Crowley, D. \& Conley, M. (1994). The $\Delta(\operatorname{argF}$-lacZ)205(U169) deletion greatly enhances resistance to hydrogen peroxide in stationary-phase Eschericbia coli. J Bacteriol 176, 1297-1302.
Woodward, M. J. \& Sullivan, G. J. (1991). Nucleotide sequence of a repetitive element isolated from Leptospira interrogans serovar bardjo type bardjo-bovis. J Gen Microbiol 137, 1101-1109.

Yasuda, B. H., Steigerwalt, A. G., Sulzer, K. R., Kaufmann, A. F., Rogers, F. \& Brenner, D. J. (1987). Deoxyribonucleic acid relatedness between serogroups and serovars in the family Leptospiraceae with proposals for seven new Leptospira species. Int J Syst Bacteriol 37, 407-415.

Zuerner, R. L. (1991). Physical map of chromosomal and plasmid DNA comprising the genome of Leptospira interrogans. Nucleic Acids Res 19, 4857-4860.

Zuerner, R. L. (1993). Genomic structure, organization, and rearrangement in Leptospira. J Cell Biochem S17E, 309.

Zuerner, R. L. (1994). Nucleotide sequence analysis of IS1533 from Leptospira borgpetersenii: identification and expression of two ISencoded proteins. Plasmid 31, 1-11.

Zuerner, R. L. \& Bolin, C. A. (1988). Repetitive sequence element cloned from Leptospira interrogans serovar hardjo type hardjo-bovis provides a sensitive diagnostic probe for bovine leptospirosis. $J$ Clin Microbiol 26, 2495-2500.

Zuerner, R. L. \& Bolin, C. A. (1990). Nucleic acid probe characterizes Leptospira interrogans serovars by restriction fragment length polymorphisms. Vet Microbiol 24, 355-366.

Zuerner, R. L., Ellis, W. A., Bolin, C. A. \& Montgomery, J. M. (1993a). Restriction fragment length polymorphisms distinguish Leptospira borgpetersenii serovar hardjo type hardjo-bovis isolates from different geographical locations. J Clin Microbiol 31, 578-583.

Zuerner, R. L., Herrmann, J. L. \& Saint Girons, I. (1993b). Comparison of genetic maps for two Leptospira interrogans serovars provides evidence for two chromosomes and intraspecies heterogeneity. J Bacteriol 175, 5445-5451.

Received 17 February 1995; revised 12 May 1995; accepted 22 May 1995. 